\title{
How Reliable The Measurement of Predictors Should Be: Monte Carlo Study in the Regression Framework
}

\author{
Agung Santoso \\ Faculty of Psychology \\ Universitas Sanata Dharma
}

\begin{abstract}
Current study investigate the effect of measurement error on the estimation of predictors that are measured either with or without error, type 1 error rates, and power to detect nonnull parameters. Author also looked for minimum value of measurement reliability needed for the analysis to provide desired results. Such value used to be based only on subjective judgements without any empirical study to support them. Simulation was conducted by manipulating the reliability of one predictor, the sample sizes, and the correlation between predictors. The model used in current study included only two predictors. The results showed that the higher the reliability of predictor measurement, the lower the bias of estimates of the two predictors and the type 1 error rates. Increasing reliability was also followed by increased power. Author also demonstrated that the minimum reliability to achieve desired results should be .8 to .9 , not .7 as suggested by others.
\end{abstract}

Keywords: reliability, regression, measurement error, bias, type 1 error rate, power

Studi ini meneliti pengaruh kesalahan pengukuran pada estimasi prediktor baik yang diukur dengan atau tanpa kesalahan, banyaknya kesalahan tipe 1, dan power untuk mendeteksi parameter yang tidak nol. Penulis juga mencari batas minimal reliabilitas pengukuran yang dibutuhkan agar analisis memberikan hasil yang memuaskan. Saat ini, nilai minimal reliabilitas hanya didasarkan pada penilaian subjektif tanpa dukungan data dari penelitian empiris. Simulasi dilakukan dengan memanipulasi reliabilitas salah satu prediktor dari dua prediktor yang digunakan, ukuran sampel, dan korelasi antara kedua prediktor. Hasil simulasi menunjukkan bahwa semakin tinggi reliabilitas pengukuran prediktor, makin rendah bias estimasi dari kedua prediktor dan banyaknya kesalahan tipe 1. Meningkatkan reliabilitas juga diikuti dengan peningkatan power. Penulis juga menunjukkan bahwa nilai reliabilitas minimal untuk memberikan hasil yang memuaskan berada pada angka .8 sampai .9 , bukan .7 seperti yang disarankan selama ini.

Kata kunci: reliabilitas, regresi, kesalahan pengukuran, bias, kesalahan tipe 1, power

Regression is the most widely used analysis technique in psychological research (Skidmore \& Thompson, 2010). The popularity of the technique is supported highly by the availability of software that can be used easily and the strengths of the technique. For example, researchers can include categorical as well as continuum variables. Researchers can also immediately evaluate Analysis of Variance (ANOVA) and Analysis of Covariance (ANCOVA) under Regression framework. The use of Ordinary Least Squares (OLS) as the estimation method also offers other strengths

Correspondence concerning this article should be addressed to Agung Santoso, Universitas Sanata Dharma Paingan, Maguwoharjo, Depok, Sleman, Yogyakarta Daerah Istimewa Yogyakarta - 55282. E-mail: agungsan_psy@yahoo.com such as unbiased and efficient parameter estimates.

Several assumptions regarding the data analyzed underlie the use of regression analysis, such as there is no model misspecification, no error of predictors' measurement, independence of observations, et cetera. A comprehensive discussion on such assumptions can be found in Berry (1993). Berry, supported by other authors such as Maxwell, Delaney, and Kelley (2003) and Pedhazur (1997), showed that the absence of predictors' error of measurement is an important assumption in regression, because violation to the assumption resulted in biased estimates of regression parameters.

Unfortunately, the assumption of no error in measuring predictors is almost always violated in psycho- 
logical research because psychological measurement can never be freed from error or in other words, psychological measurement never reach perfect reliability (Antonakis \& Dietz, 2011; Ree \& Carretta, 2006; Schmidt \& Hunter, 1999). Only in experimental studies, the assumption can be met because, in such studies, the predictors are treatment levels which can be fixed across studies leading to no measurement error introduced.

Two factors influences the estimates of regression coefficients related to measurement error, namely: (1) reliability of predictors' measurement; and (2) correlation between predictors. The reliability of predictors' measurement affects the accuracy of the estimates of regression coefficients (Cohen, Cohen, West, \& Aiken, 2002; Pedhazur, 1997). The higher the reliability of the predictors' measurement, the more accurate is the estimates of the corresponding predictors' coefficients. The lower the reliability of a predictors' measurement, the more biased is the estimates and the more conservative is the test of the regression coefficient of the corresponding predictors (Schmidt \& Hunter, 1999; Shear \& Zumbo, 2013). In a regression model involving more than one predictor, the measurement error also affects the estimates and inference of the other predictors in the model, although they have a perfect reliability or fixed levels across studies (Maxwell \& Delaney, 1993).

The effect of measurement error of one predictor to the estimate and inference of the other predictors is moderated by the size of the correlation between the two predictors (Shear \& Zumbo, 2013). The larger the correlation between the predictors, the larger the effect of measurement error is on the estimates and inference of the other predictors. When the correlation between predictors is zero, the measurement error of one predictor does not influence the other.

Many studies or writings have been published on the effect of measurement error on regression analysis. However, to the author knowledge, none of them relates the value of reliability coefficient of a predictor's measurement on the size of the bias and type 1 error comprehensively. For example, some studies only mentioned the effect of the measurement error in general without discussing the tolerable size of bias resulting from predictors' measurement with certain reliabilities (Berry, 1993; Pedhazur, 1997; Ree \& Carretta, 2006). The study conducted by Shear \& Zumbo (2013) only showed the effect of measurement error only on the type 1 error rate when the measurement has a large reliability.
Therefore, the author conducted the current study to investigate the effect of the reliability of predictors' measurement on the estimates and inferences of predictors' regression coefficients measured with and without measurement error in a model. The author conducted a Monte Carlo simulation to investigate the size of the effect of measurement error on estimates' bias and type 1 error rate. The author also wanted to provide information about the minimum reliability of a predictors' measurement in a research involving regression. Previous authors mentioned a reliability coefficient as large as 0.7 as the minimum sufficient reliability (Anastasi \& Urbina, 1997; Gregory, 2013). However, the value was based solely on subjective judgment of the authors without any support from empirical data. The current study provides a basis to determine the minimum reliability based on the size of the bias of regression estimates, their type 1 error rate and power. In the current study, the author used a more simple regression model involving only two predictors to make the effect of the measurement error clearer. However, the author believes that the results obtained from current study can be generalized to a more complex regression model.

\section{Method}

The author conducted Monte Carlo study to investigate the effect of measurement error on the estimates and inference of regression coefficients. Regression model used in current simulation was regression model with two predictors, as the following:

$$
\begin{array}{r}
y_{i}=\beta_{0}+\beta_{1} x_{1 i}+\beta_{2} x_{2 i}+\epsilon_{i} \\
x_{1 i}=T_{1 i}+\varepsilon_{i}
\end{array}
$$

where $\beta_{0}$ denotes the intercept, $\beta_{1}$ and $\beta_{2}$ denote regression coefficient for the first $\left(x_{1 i}\right)$ and second predictors $\left(x_{2 i}\right)$, respectively, while $\epsilon_{i}$ denotes regression residual. $T_{1 i}$ denotes the true score of $x_{1 i}$ and $\varepsilon_{i}$ denotes error of measurement of $x_{1 i}$. The size of $\beta_{1}$ was chosen to be moderate $\left(\beta_{1}=.39\right)$ following Cohen (1988), while $\beta_{2}$ was chosen to be zero. The size of $\beta_{0}$, or the intercept, was set to zero to make the model even more simple so the effect of measurement error on the regression coefficients can be observed more clear.

Three factors manipulated in current study were: (1) reliability of the measure of $x_{1 i}$ showing the error 
measurement size: the larger the reliability, the smaller the measurement error; (2) correlation between predictors that moderated the effect of the measurement error on the estimates and inferences of the regression coefficients; and (3) sample size: the author wanted to examine whether the sample size may reduce the effect of the measurement error on the estimates and inferences of regression coefficients.

The author chose ten reliability levels, ranging from .1 to 1 , to find the smallest reliability that will lead to tolerated level of estimation bias and type I error rate with power larger than .8. Four correlation coefficients were chosen to show four conditions: (1) when there was no correlation between predictors $\left(r_{x_{1} x_{2}}=.0\right)$; (2) correlation between predictors was small $\left(r_{x_{1} x_{2}}=.1\right)$; (3) correlation between predictors was moderate $\left(r_{x_{1} x_{2}}=.3\right)$; and (4) correlation between predictors was large $\left(r_{x_{1} x_{2}}=.5\right)$. The size of correlation coefficients was based on the size of small, medium and large correlations according to Cohen (1988).

Sample size was the third factor manipulated by the author to examine whether it moderates the effect of measurement error on estimates and inference of regression coefficients. The author chose sample sizes of $n=\{50,100,250,500,1000\}$, to represent small to large sample sizes.
The author used several criteria to determine the value of the reliability considered desirable. The first criterion was the bias of $\hat{\beta}_{1}$ (estimate of $\beta_{1}$ ), that is the regression coefficient of the variable measured with error. The reliability was considered satisfying if the bias of $\hat{\beta}_{1}$ resulting from the analysis was less than .05 in absolute value. The value of .05 was based on author's subjective judgment that such bias could still be tolerated.The second criterion was the bias of $\hat{\beta}_{2}$, that is the regression coefficient from the variable measured without measurement error. The same cutoff value of .05 was also used to determine that the reliability was satisfying.

The size of power of detecting non-null $\beta_{1}$ and type I error rate of falsely reject the null hypothesis regarding $\beta_{2}$ were the two last criterion to determine the minimum value of reliability estimate. The author use values of power $=.8$ and type I error rates $=.05$ as the cutoff values for power and type 1 error rate considered satisfying, that are usually employed in psychological research.

\section{Results}

The summary of the simulation results can be seen in Figure 1 to 4 . A more detailed simulation results

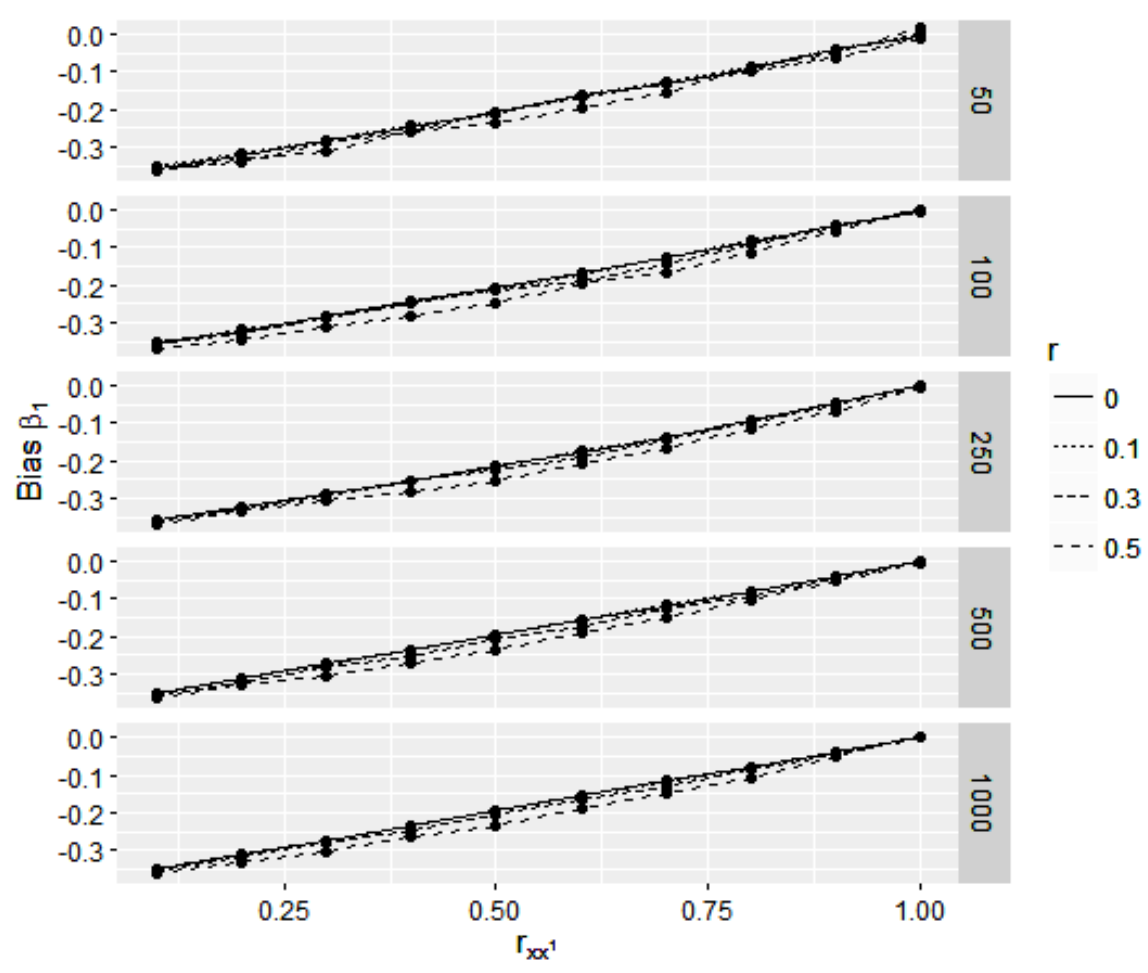

Figure 1. Line graphs showing the effect of the reliability of $x_{1 i}$ measures on the bias of $\beta_{1}$ estimates. 


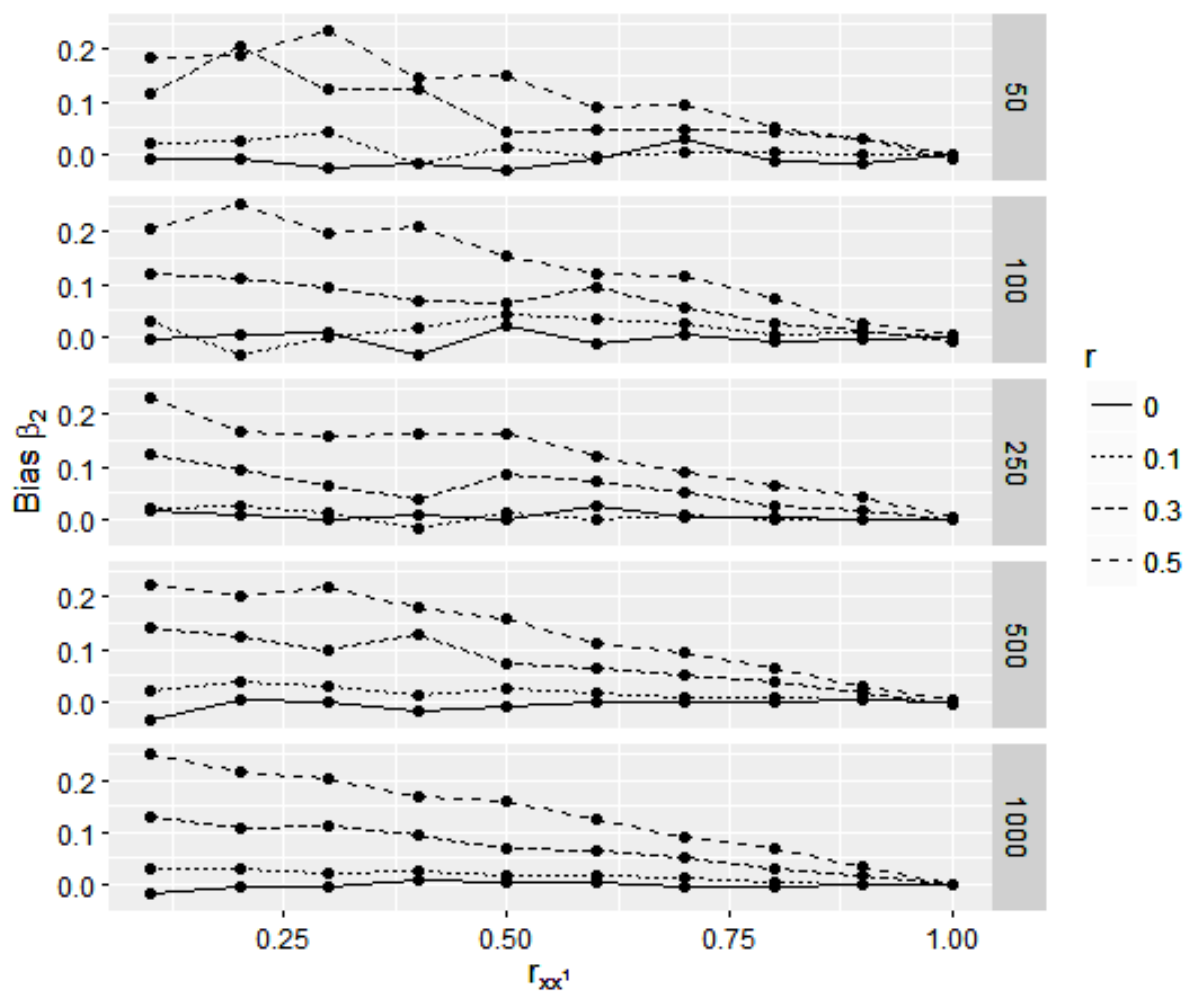

Figure 2. Line graphs showing the effect of the reliability of $x_{1 i}$ measures on the bias of $\beta_{2}$ estimates.

are provided in tables in Appendix B. Figure 1 shows the effect of the reliability of measurement of $x_{1 i}$ on the bias of $\hat{\beta}_{1}$. There are several important findings observed in Figure 1: (a) the size of the biases of $\hat{\beta}_{1}$ are homogeneous for all sample sizes and $r_{x_{1} x_{2}}$, meaning that the bias of $\hat{\beta}_{1}$ wasaffected only by the reliability of the measurement of $x_{1 i}$; (b) the bias of $\hat{\beta}_{1}$ decreases as the reliability of the measurement of $x_{1 i}$ increases; (c) the bias of the measurement of $x_{1 i}$ are negative, meaning that the presence of the measurement error made $\hat{\beta}_{1}$ values smaller than the population value; (d) when $r_{x x^{\prime}}=.7$, the value that usually suggested by several authors, the bias of the estimates is still larger than .05 in absolute value $\left(.1 \leq \frac{\sum_{R}\left(\widehat{\beta}_{1}-\beta_{1}\right)}{R} \leq .2\right)$; and (e) the reliability required to have the bias of $\hat{\beta}_{1}$ less than .05 in absolute value is .9 for all sample sizes and predictors correlation conditions.

The effect of the reliability of $x_{1 i}$ measures on the bias of $\hat{\beta}_{2}$ can be seen in Figure 2. In the figure, the bias of $\hat{\beta}_{2}$ is homogeneous for all sample sizes. The differences between sample sizes are only on their fluctuations that become smaller as the sample sizes become larger. The correlation between predictors $\left(r_{x_{1} x_{2}}\right)$ moderates the bias of $\hat{\beta}_{2}$. When the reliability of $x_{1 i}$ measure is low, the bias of $\hat{\beta}_{2}$ increases with the correlation between predictors. The bias of $\hat{\beta}_{2}$ has positive values, meaning that the estimates of $\beta_{2}$ tended to be larger than the population parameter. When the reliability of $x_{1 i}$ measure reach .7, the bias of $\hat{\beta}_{2}$ is between 0 and .1 depending on the sample sizes. The bias only becomes smaller than .05 for all sample sizes when the reliability is 1 . The bias of $\hat{\beta}_{2}$ tends to be larger when the correlations between predictors were .3 and .5 . When the correlations between predictors are .3 and .5 , the minimum reliability that leads to bias less than .05 for all sample sizes were .7 and .9 , respectively.

Figure 3 shows the effect of the reliability of $x_{1 i}$ measures on power. In the figure, it can be seen that both, the sample size and the reliability of $x_{1 i}$ measures, had an important role in determining power. The increase of sample sizes are moderated the relationship between reliability and the power to detect $\beta_{1}$ in the population. When the sample size is very large $(n=1000)$, the power of the analysis is close to 1 for all correlation conditions even when the reliability was as low as .3. When the sample size is small $(n=50)$, the power of the analysis never re- 


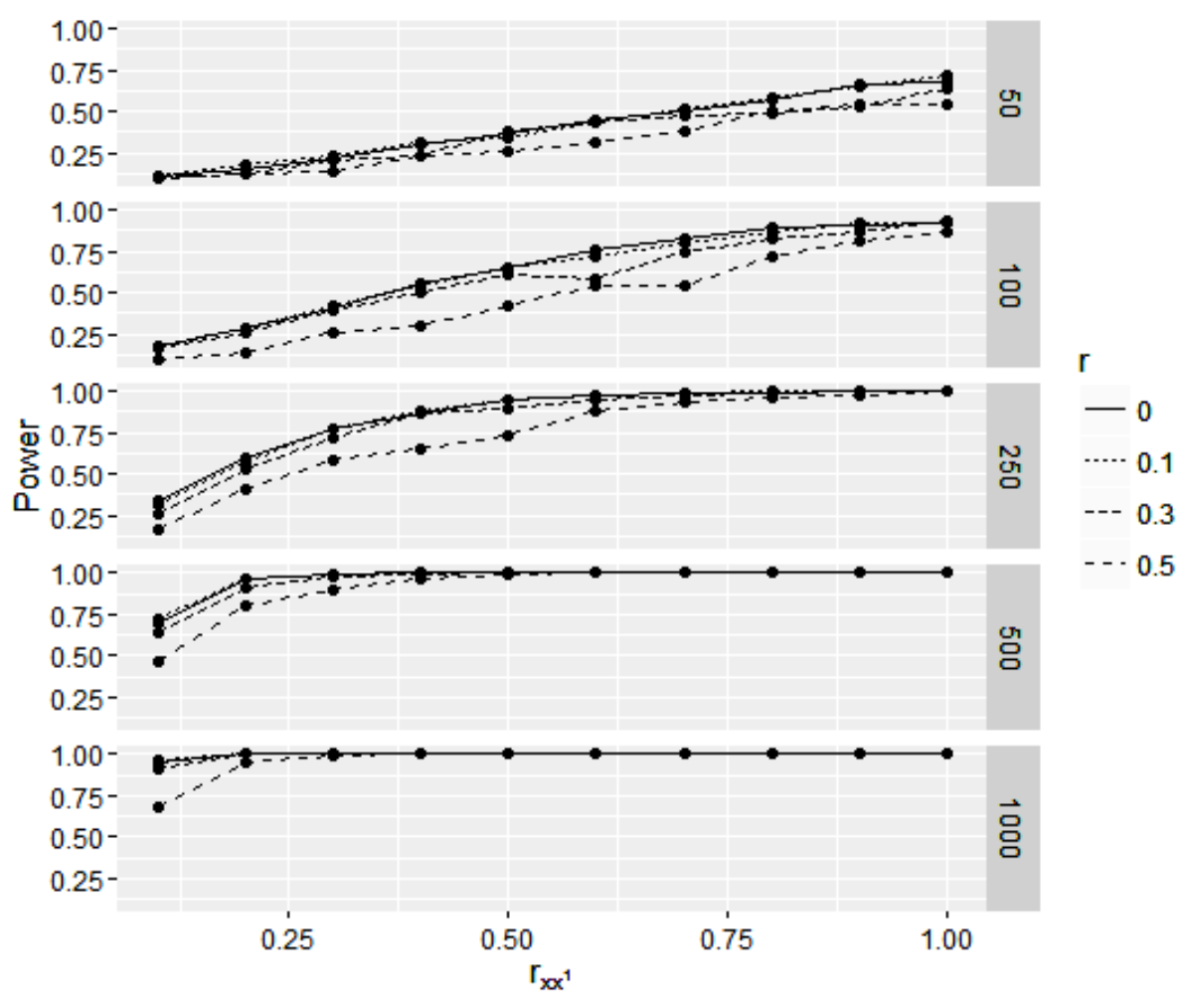

Figure 3. Line graphs showing the effect of the reliability of $x_{1 i}$ measure on the power to detect $\beta_{1}$.

aches .8 although the reliability of the measure reaches 1 . When the sample sizes are between 50 and 1000 , the reliability of the measure needed for the analysis to reach the power of .8 is at least .7 when $n=100$ and become smaller as the sample size increases.

Figure 4 shows the effect of the reliability of $x_{1 i}$ measurement to the type I error rates of $\hat{\beta}_{2}$ significance tests. The value of $\beta_{2}$ in the population was set to zero, so that a significant test is an error of inferring an effect although there is truly no effect, or type I error. The type I error rate is affected by the reliability of the measurement moderated by sample size and correlation between predictors. In lower reliability conditions, analyses conducted in smaller sample size provides smaller type I error than those in larger sample size. The smaller type I error for analysis in smaller sample size is due to their lack of power while the bias of estimating $\beta_{2}$ is still the same across all sample sizes. Figure 4 also shows that when correlation between predictors is large, the type I error rate is also larger than when the correlation between predictors is small. In higher reliability conditions, the type I error rate is small regardless of sample size and correlation between predictors.
The use of .7 as the minimum reliability still provides a larger than .05 type I error rate. For example, in a sample size of 50 when correlation between predictors is .5, the type I error rate is still .084 larger than the nominal value set in the analysis. A sample size of .9 or larger is needed to make the type I error rate close to nominal value of .05 .

\section{Discussion}

The result of the simulation supported previous findings or writings that the error of measurement increases type I error rate for predictors measured without error in the model (Berry, 1993; Maxwell \& Delaney, 1993; Ree \& Carretta, 2006; Shear \& Zumbo, 2013). The increase made the analysis reported a statistically significant effect or correlation too often from what should be expected when there is no effect in the population. The increase was moderated by the sample size and the correlation between predictors. The sample size increased the type I error rate because the power to detect an effect increased with the sample size, while the bias of the estimates still the same regardless of sample size. The correlation between predictors also affected the type I 


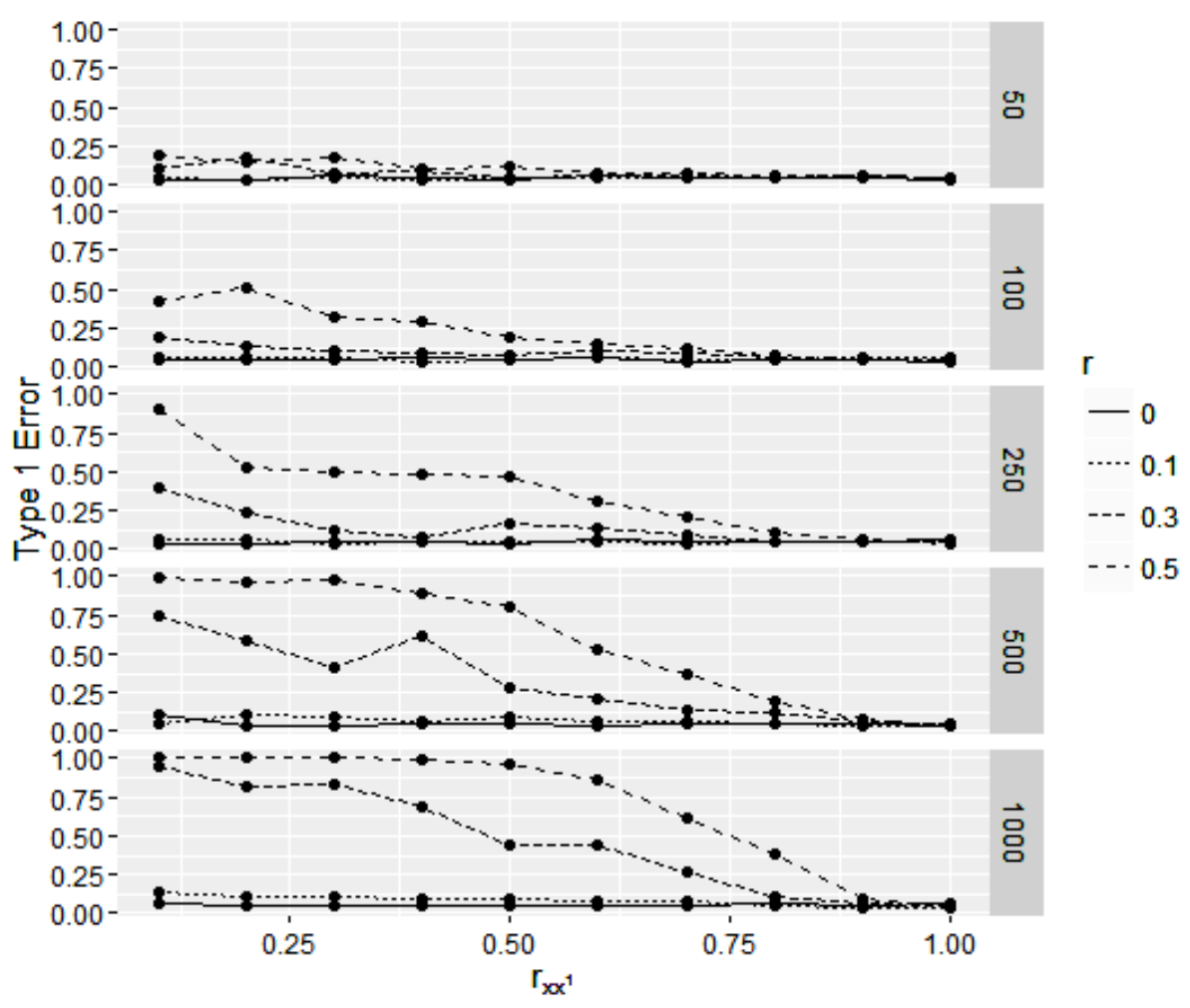

Figure 4. Line graphs showing the reliability of $x_{1 i}$ measure on type I error rates of $\beta_{2}$ significance tests.

error rate because the increased correlation between predictors made the bias of estimates larger that in turn made the significance test detected the effect too often than what should be expected when there was no effect.

The error of measurement not only lead to biased estimates of the predictor measured with error but also of the predictor measured without error. It means that although the measurement error only applied to one predictor, the bias of the estimation applied to all predictor estimated in the model. The influence of measurement error to the predictor measured with error was caused by the randomness of the measurement error that contaminated the correlation between the predictor and criterion. The relationship between the true regression coefficient and observed regression coefficient can be expressed as the following (proof is provided in Appendix A):

$$
\beta_{t_{1} y}=\frac{\beta_{1}}{r_{x x^{\prime}}}
$$

In equation (3), $\beta_{t_{1} y}$, the true regression coefficient, was larger than or equal to $\beta_{1}$, the observed regression coefficient, because $r_{x x}$ 'was between 0 and 1 . Therefore, the bias of the estimation $\left(\hat{\beta}_{1}-\beta_{t_{1} y}\right)$ was less than or equal to zero and could not be positive. In other words, the regression coefficient obtained when there was measurement error was smaller than the true coefficient.

On the other hand, the bias of the estimates of the predictor measured without error was positive. The coefficient of the predictor can be expressed mathematically as the following:

$$
\begin{array}{r}
\beta_{2}=\frac{r_{\mathrm{y} 2}-r_{12} * \mathrm{r}_{\mathrm{y} 1}}{\sqrt{\left(1-\mathrm{r}_{12}^{2}\right) *\left(1-\mathrm{r}_{\mathrm{y} 1}^{2}\right)}} \\
\beta_{2}=\frac{\left(r_{y 2}-r_{t_{1} x_{2}} * \sqrt{\left.r_{x x^{\prime}} * r_{t_{1}} y^{*} \sqrt{r_{x x^{\prime}}}\right)}\right.}{\sqrt{\left(1-r_{t_{1} x_{2}}^{2} * r_{x x^{\prime}}\right) *\left(1-r_{t_{1} y^{2}}^{*} r_{x x^{\prime}}\right)}}
\end{array}
$$

In equation (4) when $r_{x x}$ ' decreases, the numerator become larger and simultaneously the denominator become smaller. The increase of numerator and decrease of denominator make $\beta_{2}$ become larger.

Power to detect significant regression coefficient of the predictor measured with error became smaller with the reliability. The decrease in power was caused by the negative bias of the estimates making the observed coefficient smaller than the true coefficient, the coefficient when there was no measurement error. 
The simulation results also showed that the cutoff value of the reliability suggested by several authors did not lead to satisfying analysis result in terms of estimation bias, type I error rate and power. The author found that the measure of the predictor had to be at least .9 for the analysis to provide satisfying results.

Two limitations of current study should be noted. First, the author only included one predictor measured with error and one other predictor measured without error. Although the author believe that the results can be generalized to more complex model, the cutoff value for the reliability may differ, therefore need further scrutiny. The author only investigated regression analysis, which allows the analysis of observed variables only. The results may not be generalized to analysis techniques capable of including latent variables.

\section{Conclusion}

The current study was conducted to address two questions about the effect of measurement error on regression analysis and the minimum reliability providing satisfactory results. The results of the study shows that the measurement error leads to biased estimates of regression coefficient of the predictor measured with or without error. The error of measurement also inflates the type I error rates and reduce the power of the analysis. The effect of measurement error is homogeneous across all sample size but increases with the increase of correlation between predictors. The sample size moderates the effect of measurement error on type I error and power, in which sample size strengthen the effect of measurement error on type I error rates but weaken its effect on power.

Findings from the current study also showed that the minimum value of reliability that has been suggested by many authors has not provided satisfactory analysis result. The analysis provided satisfying results only when the reliability of the predictor was .9 .

\section{Recommendation}

Based on the result of the current study, the author recommend researchers to use measurement instruments that have reliability as high as possible to avoid problems correspond to lack of reliability. The value of .9 is suggested as the minimum reliability of the predictor measurement that will produce small bias estimates, small type I error rates and larger po- wer. The utility of analysis technique accommodating the inclusion of latent variables may reduce the effect of measurement error, although further study needs to be conducted to confirm such suggestion. The future study may include more complex models including interaction between predictors to examine whether the minimum value suggested in this study can be applied to such studies.

\section{References}

Anastasi, A., \& Urbina, S. (1997). Psychological Testing (7th ed.). Upper Saddle River, N.J.: Pearson. Antonakis, J., \& Dietz, J. (2011). Looking for validity or testing it? The perils of stepwise regression, extreme-scores analysis, heteroscedasticity, and measurement error. Personality and Individual Differences, 50(3), 409-415. https:// doi.org/10.1016/j.paid.2010.09.014

Berry, W. D. (1993). Understanding regression assumptions. Newbury Park: SAGE Publications.

Cohen, J. (1988). Statistical power analysis for the behavioral sciences (2nd ed.). Hillsdale, N.J.: Routledge.

Cohen, J., Cohen, P., West, S. G., \& Aiken, L. S. (2002). Applied multiple regression/correlation analysis for the behavioral sciences (3rd ed.). Mahwah, N.J.: Routledge.

Gregory, R. J. (2013). Psychological testing: History, principles and applications (7th ed.). Boston: Pearson.

Maxwell, S. E., \& Delaney, H. D. (1993). Bivariate median splits and spurious tatistical significance. Psychological Bulletin, 113(1), 181-190. https:// doi.org/10.1037/0033-2909.113.1.181

Maxwell, S. E., Delaney, H. D., \& Kelley, K. (2003). Designing experiments and analyzing data: $A$ model comparison perspective (2nd ed.). Mahwah, N.J.: Routledge.

Pedhazur, E. J. (1997). Multiple regression in behavioral research (3rd ed.). Fort Worth: Wadsworth Publishing.

Ree, M. J., \& Carretta, T. R. (2006). The role of measurement error in familiar statistics. Organizational Research Methods, 9(1), 99-112. https:// doi.org/10.1177/1094428105283192

Schmidt, F. L., \& Hunter, J. E. (1999). Theory testing and measurement error. Intelligence, 27(3), 183-198. https://doi.org/10.1016/S0160-2896(99) 00024-0

Shear, B. R., \& Zumbo, B. D. (2013). False posi- 
tives in multiple regression: Unanticipated consequences of measurement error in the predictor variables. Educational and Psychological Measurement, 73(5), 733-756. https://doi.org/10.11 $77 / 0013164413487738$
Skidmore, S. T., \& Thompson, B. (2010). Statistical techniques used in published articles: A historical review of reviews. Educational and Psychological Measurement, 70(5), 777-795. https://doi. org/10.1177/0013164410379320

\section{Appendix A}

Proof of Equation (3)

$$
\begin{gathered}
\beta_{t y}=\frac{\operatorname{cov}(t, y)}{\sigma_{t}^{2}} \Leftrightarrow \operatorname{cov}(t, y)=\sigma_{t}^{2} * \beta_{t y} \\
\beta_{1}=\frac{\operatorname{cov}(x, y)}{\sigma_{x}^{2}}=\frac{\operatorname{cov}(t+e, y)}{\sigma_{x}^{2}}=\frac{\operatorname{cov}(t, y)+\operatorname{cov}(e, y)}{\sigma_{x}^{2}}
\end{gathered}
$$

Because $e$ is random then $\operatorname{cov}(e, y)=0$. Therefore,

$$
\beta_{1}=\frac{\operatorname{cov}(t, y)}{\sigma_{x}^{2}}=\beta_{t y} * \frac{\sigma_{t}^{2}}{\sigma_{x}^{2}}
$$

Because

$$
r_{x x^{\prime}}=\frac{\sigma_{t}^{2}}{\sigma_{x}^{2}}
$$

Then

$$
\begin{gathered}
\beta_{1}=\beta_{t y} * r_{x x^{\prime}} \\
\beta_{t y}=\frac{\beta_{1}}{r_{x x^{\prime}}}
\end{gathered}
$$




\section{Appendix B1}

Mean of $\hat{\beta}_{1}$ and $\hat{\beta}_{2}$ from 1000 Replications

\begin{tabular}{|c|c|c|c|c|c|c|c|c|c|c|c|}
\hline \multirow[b]{2}{*}{$r_{12}$} & \multirow[b]{2}{*}{$r_{x x}$} & \multicolumn{2}{|c|}{$n=50$} & \multicolumn{2}{|c|}{$n=100$} & \multicolumn{2}{|c|}{$n=250$} & \multicolumn{2}{|c|}{$n=500$} & \multicolumn{2}{|c|}{$n=1000$} \\
\hline & & $\hat{\beta}_{1}$ & $\hat{\beta}_{2}$ & $\hat{\beta}_{1}$ & $\hat{\beta}_{2}$ & $\hat{\beta}_{1}$ & $\hat{\beta}_{2}$ & $\hat{\beta}_{1}$ & $\hat{\beta}_{2}$ & $\hat{\beta}_{1}$ & $\hat{\beta}_{2}$ \\
\hline 0 & 1 & 0.385 & .000 & 0.383 & 0.002 & 0.390 & 0.002 & .390 & -0.001 & 0.389 & 0.000 \\
\hline 0 & 0.9 & 0.352 & -0.016 & 0.348 & -0.006 & 0.343 & -0.001 & 0.352 & 0.003 & 0.353 & -0.001 \\
\hline 0 & 0.8 & 0.296 & -0.012 & 0.307 & -0.007 & 0.299 & 0.004 & 0.313 & -0.002 & 0.311 & -0.004 \\
\hline 0 & 0.7 & 0.258 & 0.030 & 0.265 & 0.005 & 0.253 & 0.002 & 0.272 & -0.001 & 0.273 & -0.003 \\
\hline 0 & 0.6 & 0.227 & -0.007 & 0.224 & -0.013 & 0.214 & 0.025 & 0.234 & 0.000 & 0.233 & 0.006 \\
\hline 0 & 0.5 & 0.183 & -0.031 & 0.183 & 0.020 & 0.177 & 0.000 & 0.195 & -0.007 & 0.196 & 0.003 \\
\hline 0 & 0.4 & 0.145 & -0.017 & 0.145 & -0.035 & 0.134 & 0.009 & 0.156 & -0.016 & 0.157 & 0.009 \\
\hline 0 & 0.3 & 0.107 & -0.026 & 0.106 & 0.010 & 0.101 & -0.001 & 0.117 & 0.001 & 0.116 & -0.005 \\
\hline 0 & 0.2 & 0.068 & -0.011 & 0.069 & 0.005 & 0.067 & 0.010 & 0.078 & 0.003 & 0.078 & -0.003 \\
\hline 0 & 0.1 & 0.035 & -0.009 & 0.036 & -0.006 & 0.033 & 0.017 & 0.038 & -0.035 & 0.038 & -0.015 \\
\hline 0.1 & 1 & 0.393 & 0.001 & 0.388 & 0.001 & 0.389 & 0.001 & 0.393 & 0.000 & 0.390 & 0.001 \\
\hline 0.1 & 0.9 & 0.350 & 0.001 & 0.346 & 0.010 & 0.344 & 0.002 & 0.350 & 0.003 & 0.350 & 0.001 \\
\hline 0.1 & 0.8 & 0.304 & 0.005 & 0.308 & 0.005 & 0.298 & 0.001 & 0.309 & 0.011 & 11 & 0.005 \\
\hline 0.1 & 0.7 & 0.264 & 0.003 & 0.263 & 0. & 52 & 0.008 & 4 & 8 & 71 & 0.012 \\
\hline 0.1 & 0.6 & 0.227 & -0.003 & 0.215 & 0.036 & 0.215 & 0.000 & 0.232 & 0.016 & 0.233 & 0.019 \\
\hline 0.1 & 0.5 & 0.179 & 0.012 & 0.179 & 0.043 & 0.172 & 0.012 & 0.193 & 0.027 & 0.194 & 0.020 \\
\hline 0.1 & 0.4 & 0.146 & -0.015 & 0.145 & 0.016 & 0.137 & -0.016 & 0.155 & 0.012 & 0.156 & 0.024 \\
\hline 0.1 & 0.3 & 0.106 & 0.042 & 0.104 & 0.001 & 0.102 & 0.015 & 0.117 & 0.030 & 0.117 & 0.022 \\
\hline 0.1 & 0.2 & 0.075 & 0.025 & 0.071 & -0. & 0.066 & 0.024 & 0.079 & 0.039 & 777 & 0.029 \\
\hline 0.1 & 0.1 & 0.036 & 0.021 & 0 . & 0. & 0.032 & 0.021 & 0 & 0.021 & 39 & 0.032 \\
\hline 0.3 & 1 & 0.379 & 0.001 & 0.393 & -0.008 & 0.391 & -0.001 & 0.390 & -0.003 & 0.391 & 0.001 \\
\hline 0.3 & 0.9 & 0.329 & 0.030 & 0.344 & 0.014 & 0.338 & 0.018 & 0.346 & 0.017 & 0.344 & 0.019 \\
\hline 0.3 & 0.8 & 0.290 & 0.041 & 0.299 & 0.024 & 0.291 & 0.027 & 0.300 & 0.041 & 0.305 & 0.028 \\
\hline 0.3 & 0.7 & 0.257 & 0.045 & 0.248 & 0.056 & 0.248 & 0.050 & 0.264 & 0.052 & 0.261 & 0.050 \\
\hline 0.3 & 0.6 & 0.223 & 0.048 & 0.197 & 0.094 & 0.199 & 0.072 & 0.220 & 0.065 & 0.221 & 0.067 \\
\hline 0.3 & 0.5 & 0.181 & 0.042 & 0.175 & 0.063 & 0.164 & 0.085 & 0.184 & 0.074 & 0.184 & 0.071 \\
\hline 0.3 & 0.4 & 0.129 & 0.126 & 0.140 & 0.070 & 0.134 & 0.041 & 0.137 & 0.129 & 0.145 & 0.093 \\
\hline 0.3 & 0.3 & 0.102 & 0.126 & 0.105 & 0.094 & 0.097 & 0.066 & 0.109 & 0.098 & 0.107 & 0.111 \\
\hline 0.3 & 0.2 & 0.052 & 0.207 & 0.063 & 0.113 & 0.061 & 0.094 & 0.071 & 0.123 & 0.073 & 0.107 \\
\hline 0.3 & 0.1 & 0.035 & 0.116 & 0.031 & 0.118 & 0.028 & 0.125 & 0.035 & 0.140 & 0.035 & 0.130 \\
\hline 0.5 & 1 & 0.406 & -0.011 & 0.392 & 0.005 & 0.387 & 0.003 & 0.387 & 0.003 & 0.390 & -0.001 \\
\hline 0.5 & 0.9 & 0.339 & 0.031 & 0.333 & 0.026 & 0.322 & 0.044 & 0.337 & 0.032 & 0.338 & 0.035 \\
\hline 0.5 & 0.8 & 0.304 & 0.050 & 0.277 & 0.072 & 0.278 & 0.065 & 0.288 & 0.064 & 0.283 & 0.071 \\
\hline 0.5 & 0.7 & 0.235 & 0.093 & 0.221 & 0.117 & 0.225 & 0.092 & 0.241 & 0.096 & 0.240 & 0.091 \\
\hline 0.5 & 0.6 & 0.196 & 0.089 & 0.195 & 0.121 & 0.182 & 0.120 & 0.202 & 0.113 & 0.198 & 0.126 \\
\hline 0.5 & 0.5 & 0.151 & 0.148 & 0.145 & 0.155 & 0.137 & 0.164 & 0.152 & 0.157 & 0.156 & 0.158 \\
\hline
\end{tabular}




\begin{tabular}{|c|c|c|c|c|c|c|c|c|c|c|c|}
\hline \multirow[b]{2}{*}{$r_{12}$} & \multirow[b]{2}{*}{$r_{x x}$} & \multicolumn{2}{|c|}{$n=50$} & \multicolumn{2}{|c|}{$n=100$} & \multicolumn{2}{|c|}{$n=250$} & \multicolumn{2}{|c|}{$n=500$} & \multicolumn{2}{|c|}{$n=1000$} \\
\hline & & $\hat{\beta}_{1}$ & $\hat{\beta}_{2}$ & $\hat{\beta}_{1}$ & $\hat{\beta}_{2}$ & $\hat{\beta}_{1}$ & $\hat{\beta}_{2}$ & $\hat{\beta}_{1}$ & $\hat{\beta}_{2}$ & $\hat{\beta}_{1}$ & $\hat{\beta}_{2}$ \\
\hline 0.5 & 0.4 & 0.128 & 0.147 & 0.107 & 0.209 & 0.106 & 0.163 & 0.120 & 0.179 & 0.123 & 0.169 \\
\hline 0.5 & 0.3 & 0.078 & 0.236 & 0.079 & 0.196 & 0.083 & 0.158 & 0.084 & 0.220 & 0.087 & 0.201 \\
\hline 0.5 & 0.2 & 0.055 & 0.187 & 0.044 & 0.252 & 0.054 & 0.170 & 0.060 & 0.200 & 0.056 & 0.216 \\
\hline 0.5 & 0.1 & 0.027 & 0.185 & 0.024 & 0.207 & 0.020 & 0.231 & 0.028 & 0.225 & 0.026 & 0.249 \\
\hline
\end{tabular}




\section{Appendix B2}

Percentage of $\hat{\beta}_{1}$ and $\hat{\beta}_{2}$ Statistical Tests Providing Significant Result from 1000 Replications

\begin{tabular}{|c|c|c|c|c|c|c|c|c|c|c|c|}
\hline \multirow[b]{2}{*}{$r_{12}$} & \multirow[b]{2}{*}{$x x$} & \multicolumn{2}{|c|}{$n=50$} & \multicolumn{2}{|c|}{$n=100$} & \multicolumn{2}{|c|}{$n=250$} & \multicolumn{2}{|c|}{$n=500$} & \multicolumn{2}{|c|}{$n=1000$} \\
\hline & & $\hat{\beta}_{1}$ & $\hat{\beta}_{2}$ & $\hat{\beta}_{1}$ & $\hat{\beta}_{2}$ & $\hat{\beta}_{1}$ & $\hat{\beta}_{2}$ & $\hat{\beta}_{1}$ & $\hat{\beta}_{2}$ & $\hat{\beta}_{1}$ & $\hat{\beta}_{2}$ \\
\hline 0 & 1 & 0.678 & 0.04 & .927 & 0.039 & 0.999 & 0.061 & 000 & 0.042 & 000 & 4 \\
\hline 0 & 0.9 & 0.66 & 0.053 & 0.914 & 0.049 & 1.000 & 0.054 & 1.000 & 0.043 & 1.000 & 0.046 \\
\hline 0 & 0.8 & 0.567 & 0.047 & 0.898 & 0.052 & 0.996 & 0.045 & 1.000 & 0.050 & 1.000 & 0.067 \\
\hline 0 & 0.7 & 0.497 & 0.045 & 0.822 & 0.041 & 0.989 & 0.053 & 1.000 & 0.043 & 1.000 & 0.055 \\
\hline 0 & 0.6 & 0.45 & 0.056 & 0.765 & 0.059 & 0.975 & 0.071 & 1.000 & 0.036 & 1.000 & 0.055 \\
\hline 0 & 0.5 & 0.367 & 0.038 & 0.649 & 0.054 & 0.955 & 0.040 & 1.000 & 0.047 & 1.000 & 0.048 \\
\hline 0 & 0.4 & 0.294 & 0.046 & 0.562 & 0.067 & 0.869 & 0.046 & 0.999 & 0.053 & 1.000 & 0.049 \\
\hline 0 & 0.3 & 0.218 & 0.056 & 0.411 & 0.054 & 0.771 & 0.047 & 0.994 & 0.039 & 1.000 & 0.044 \\
\hline 0 & 0.2 & 0.149 & 0.031 & 0.286 & 0.053 & 0.603 & 0.042 & 0.964 & 0.033 & 1.000 & 0.049 \\
\hline 0 & 0.1 & 0.108 & 0.031 & 0.178 & 0.044 & 0.337 & 0.042 & 0.698 & 0.111 & 0.947 & 0.070 \\
\hline 0.1 & 1 & 0.718 & 0.045 & 0.92 & 0.058 & 0.998 & 0.046 & 1.000 & 0.048 & 1.000 & 0.040 \\
\hline 0.1 & 0.9 & 0.654 & 0.062 & 0.915 & 0.062 & 0.997 & 0.047 & 1.000 & 0.042 & 1.000 & 0.038 \\
\hline 0.1 & 0.8 & 0.589 & 0.046 & 0.873 & 0.046 & 0.997 & 0.052 & 1.000 & 0.056 & 1.000 & 0.049 \\
\hline 0.1 & 0.7 & 0.516 & 0 & 0 . & 0.051 & 0.992 & 0.039 & 1.000 & 60 & 1.000 & 0.073 \\
\hline 0.1 & 0.6 & 0.435 & 0.046 & 0.717 & 0.058 & 0.976 & 0.053 & 1.000 & 0.061 & 1.000 & 0.076 \\
\hline 0.1 & 0.5 & 0.335 & 0.048 & 0.65 & 0.055 & 0.948 & 0.044 & 1.000 & 0.093 & 1.000 & 0.087 \\
\hline 0.1 & 0.4 & 0.314 & 0.034 & 0.546 & 0.038 & 0.880 & 0.044 & 1.000 & 0.063 & 1.000 & 0.100 \\
\hline 0.1 & 0.3 & 0.229 & 0.055 & 0.415 & 0.058 & 0.767 & 0.039 & 0.997 & 0.089 & 1.000 & 0.109 \\
\hline 0.1 & 0.2 & 0.172 & 0.038 & 0.2 & 62 & 0.570 & 0.057 & 0.962 & 0.114 & 0.999 & 0.110 \\
\hline 0.1 & 0.1 & 0.104 & 0 & 0.175 & 2 & 3 & 50 & 0.717 & 0.047 & 67 & 0.131 \\
\hline 0.3 & 1 & 0.631 & 0.041 & 0.94 & 0.046 & 1.000 & 0.052 & 1.000 & 0.052 & 1.000 & 0.048 \\
\hline 0.3 & 0.9 & 0.524 & 0.063 & 0.866 & 0.043 & 0.999 & 0.051 & 1.000 & 0.060 & 1.000 & 0.068 \\
\hline 0.3 & 0.8 & 0.494 & 0.049 & 0.829 & 0.061 & 0.994 & 0.055 & 1.000 & 0.118 & 1.000 & 0.114 \\
\hline 0.3 & 0.7 & 0.479 & 0.061 & 0.752 & 0.092 & 0.979 & 0.095 & 1.000 & 0.143 & 1.000 & 0.265 \\
\hline 0.3 & 0.6 & 0.434 & 0.06 & 0.58 & 0.111 & 0.946 & 0.138 & 1.000 & 0.205 & 1.000 & 0.444 \\
\hline 0.3 & 0.5 & 0.378 & 0.051 & 0.605 & 0.078 & 0.895 & 0.159 & 0.999 & 0.284 & 1.000 & 0.445 \\
\hline 0.3 & 0.4 & 0.236 & 0.097 & 0.507 & 0.089 & 0.867 & 0.085 & 0.992 & 0.614 & 1.000 & 0.689 \\
\hline 0.3 & 0.3 & 0.209 & 0.081 & 0.393 & 0.1 & 0.724 & 0.126 & 0.981 & 0.416 & 1.000 & 0.829 \\
\hline 0.3 & 0.2 & 0.121 & 0.175 & 0.253 & 0.137 & 0.530 & 0.231 & 0.913 & 0.592 & 0.998 & 0.814 \\
\hline 0.3 & 0.1 & 0.098 & 0.1 & 0.17 & 0.194 & 0.264 & 0.401 & 0.634 & 0.746 & 0.903 & 0.946 \\
\hline 0.5 & 1 & 0.537 & 0.045 & 0.864 & 0.046 & 0.997 & 0.040 & 1.000 & 0.042 & 1.000 & 0.047 \\
\hline 0.5 & 0.9 & 0.537 & 0.049 & 0.808 & 0.053 & 0.971 & 0.068 & 1.000 & 0.073 & 1.000 & 0.101 \\
\hline 0.5 & 0.8 & 0.503 & 0.065 & 0.716 & 0.079 & 0.969 & 0.113 & 1.000 & 0.194 & 1.000 & 0.389 \\
\hline 0.5 & 0.7 & 0.377 & 0.084 & 0.544 & 0.126 & 0.931 & 0.209 & 1.000 & 0.372 & 1.000 & 0.611 \\
\hline 0.5 & 0.6 & 0.312 & 0.077 & 0.548 & 0.151 & 0.879 & 0.313 & 1.000 & 0.521 & 1.000 & 0.863 \\
\hline 0.5 & 0.5 & 0.255 & 0.119 & 0.426 & 0.198 & 0.735 & 0.474 & 0.987 & 0.804 & 1.000 & 0.968 \\
\hline
\end{tabular}




\begin{tabular}{|c|c|c|c|c|c|c|c|c|c|c|c|}
\hline \multirow[b]{2}{*}{$r_{12}$} & \multirow[b]{2}{*}{$r_{x x}$} & \multicolumn{2}{|c|}{$n=50$} & \multicolumn{2}{|c|}{$n=100$} & \multicolumn{2}{|c|}{$n=250$} & \multicolumn{2}{|c|}{$n=500$} & \multicolumn{2}{|c|}{$n=1000$} \\
\hline & & $\hat{\beta}_{1}$ & $\hat{\beta}_{2}$ & $\hat{\beta}_{1}$ & $\hat{\beta}_{2}$ & $\hat{\beta}_{1}$ & $\hat{\beta}_{2}$ & $\hat{\beta}_{1}$ & $\hat{\beta}_{2}$ & $\hat{\beta}_{1}$ & $\hat{\beta}_{2}$ \\
\hline 0.5 & 0.4 & 0.226 & 0.111 & 0.306 & 0.288 & 0.648 & 0.487 & 0.967 & 0.891 & 1.000 & 0.989 \\
\hline 0.5 & 0.3 & 0.135 & 0.181 & 0.254 & 0.327 & 0.587 & 0.502 & 0.891 & 0.976 & 0.996 & 0.999 \\
\hline 0.5 & 0.2 & 0.129 & 0.143 & 0.132 & 0.51 & 0.410 & 0.522 & 0.805 & 0.957 & 0.951 & 1.000 \\
\hline 0.5 & 0.1 & 0.094 & 0.188 & 0.101 & 0.419 & 0.160 & 0.900 & 0.460 & 0.984 & 0.675 & 1.000 \\
\hline
\end{tabular}

